\title{
The Identity of Patients in 12th Century Medical Text in Persian: a Sociolinguistic Perspective
}

\author{
Manizheh Abdollahi \\ Persian Dept., Paramedical School, Shiraz University of Medical Sciences, Shiraz, Iran \\ Tel: 00989173118082 E-mail: manijeh.abdolahi@gmail.com \\ Sammad Sajjadi \\ English Dept., Paramedical School, Shahid Beheshti University of Medical Sciences, Tehran, Iran \\ Tel: 00989126260258 E-mail: ssajjadi2001@yahoo.com \\ Ehya Amalsaleh (Corresponding author) \\ English Dept., Paramedical School, Shiraz University of Medical Sciences, Shiraz, Iran \\ Tel: 00989171206197 E-mail: asalehe@yahoo.com
}

Received: 13-01-2013

doi:10.7575/aiac.ijalel.v.2n.3p.1
Accepted: 11-02-2013

Published: 01-05-2013

\begin{abstract}
This study investigates linguistic expressions featuring the patient in a medical textbook written in the 12th century in Persian. At this time, medical practice is noticed to be more scientific than those written years before or even many centuries after because, keeping a distance from superstitious views, the practice follows the scientific procedures of the day. The present study adopts a sociolinguistics perspective to examine the social status of the patient in the text. The textbook - "Khofi Alayee" - was chosen to be examined mainly because it was considered as a scientific book written for public use; also it was published as a kind of pocket book for people to use while on trip or, more importantly, when the doctors were in emergency situations. This text, like other medical texts, is expected to be written impartially, but this is not usually the case. The result of the study showed that the patient was primarily viewed as an object with no social status considered for revered citizen. On the other hand, in occasions when the patient was treated as a person, he represented a male belonging to the middle or higher classes of the society.
\end{abstract}

Keywords: Patient identity, power, gender, CDA

\section{Introduction and Review of Literature}

\subsection{Linguistic Background}

Language is the medium through which our outlook and ideology is formed. It can affect the way(s) people in a community position themselves and relate themselves with other members of the community. The attitude shaped this way, in turn, contributes to the formation of certain cultural and social issues, including status and gender differences which usually appear as something natural and common sense. This is where critical linguists have to play their role by attempting to "defamiliarise" these taken-for-granted notions (Fowler, 1996). Moreover, since the ideology of the writer or producer of the text is integrated with the text, Fowler (1996) maintains that, the critical linguists should "uncover the ideology" hidden in the text. The term 'ideology' within the framework of Critical Discourse Analysis (henceforth CDA) is defined as: “. .. the basic system of principles that underlie the social representations (knowledge, attitude) of a group. Such ideologies consist of all propositions that are implied by all attitudes of a group..." (van Dijk, 1997a). Van Dijk (2000.) considers ideology as a system of beliefs which is socially shared among the members of a group, society, etc. He further points out that "[I]n the same way that we do not speak of individual languages, we do not have individual ideologies. So ideologies consist of shared, social beliefs and not of personal opinions" (p 11). And the most common medium through which ideologies are transmitted is language. Language, in fact, act as a niche for ideologies; it provides a safe place for ideologies to be formed and then disseminated. Language, then, is believed to shape behavior, as well as the way we feel and think. In addition to forming ideology, language can even change our social reality (Bourdieu, 1997). It seems, therefore, necessary to make people aware of what language can do in defining people and their status in a community. Such views on the significance and function of language, in different contexts, are sound enough to justify carrying out investigations, like the current study, in academic fields.

From the points indicated above, it is understood that within the realm of discourse, the development of conceptual frameworks, ideologies, hegemonies and many other social issues can be exercised and constituted through language. This makes discourse analysis function as a tool for deconstructing such issues. Discourse analysts, by studying how language is built beyond sentences, tend to explore the relationship between sentences and larger segments of a text. Discourse analysis takes a text as its point of departure rather than the isolated sentences; it goes beyond individual sentences to analyze the function of the language used in specific contexts ( van Dijk, 1997b, Sheffrin, et al., 2001) This 
approach attempts to investigate different structures the speaker/writer employs in order to fulfill different purposes in different contexts of situation. The interplay between the structure and function of the language has been studied and investigated a lot by the proponents of the functional grammar; they argue that language is used by its speakers/writers to meet their needs. Viewing language from the functional perspective, Halliday (1989) adopts the "systemic theory" to analyze texts. This is "a theory of meaning as a choice, by which a language, ..., is interpreted as networks of interlocking options" (p. xiv). Systemic Functional theory, according to Chapelle (1998), views language as a social semiotic, a resource that people use to accomplish their purposes by expressing meanings in context. The functional grammar, then, tends to relate the form of language to the intended meaning. It is used in an attempt to show how the structure of language is determined by the way it is used by the speakers of the language. Halliday (1989) holds that language lies within a system, an obligatory system, within which, depending upon their purpose, the speakers/writers have certain options. Selection from among different options available can reveal the user's worldview. Hence, choosing one form/structure over the other is not usually a matter of chance; rather, since a particular form may imply a certain function, preferring one form over the other can display the speaker/writer's intention(s). That is to say, the speaker/writer chooses a particular linguistic form to accomplish the social purpose(s) he/she has in mind. Thus, the description of the language inevitably demands the description of the choice(s) made.

Grounded in the Systemic Functional Linguistics (SFL), CDA, also, takes the speaker/writer's choices as systematic ones. Choice, in fact, plays a central role in SFL. (Halliday, 1969). In fact, CDA proponents (Fairclough, 1989; Fowler, 1996; Kress, 1996; and van Dijk, 1997a), consider CDA as a new kind of discourse analysis. The difference found between these two approaches is not, as Hammersley (1997) indicates, the employment of an analytic technique; rather, it is basically an attempt "to locate discourse within a particular conception of society and its adoption of a thoroughgoingly "critical' attitude towards that society" (p. 237). But the question raised by Candlin, as cited by Pennycook (2001), seeks to know what the critical applied linguistics is and why we require it at all. Candlin then maintains that such an instrument intended to uncover "the hidden connections... between language structure and social structure" (Pennycook, 2001, 70). In the same vein, Fairclough (1995), while taking a social view towards analyzing texts, finds the systemic-functional linguistics a potent theory enabling one to analyze both what is 'present' in the text and what is 'absent' there. Furthermore, since this approach "emphasizes choice, the selection of options from systems constitutes meaning potentials (...). Choice entails exclusion as well as inclusion." (p.210). He refers to discourse as the "use of language seen as a form of social practice" and to discourse analysis as the "analysis of how texts work within sociocultural practice" (p.210). In particular, he considers language as 'social practice' acting as both the product of communication and the process (the medium) through which communication takes place. According to Fairclough (1989), we have to analyze "the relationship between texts, processes and their social condition" (p.26). This view has provided discourse analysts with a tool, enabling them to describe, interpret, and explain the discourse. Fairclough makes a distinction between a text and discourse, considering the latter "a process of production, of which text is a product and the process of interpretation, for which text is a resource" (p. 24)). That is to say, the analysis moves away from focusing on the "whatness" of the text (description) towards concentrating on the "howness" and "whyness" of the text (interpretation and explanation, respectively). CDA, according to Fairclough (1989), is to display why the speaker/writer, among the array of language structures and modes, selects just certain forms or modes. And this whyness is of special importance in the CDA approach since it enables the individual to explain "the relationship between interaction and social context... with the social determination of the process of production and interpretation and their social effects" (Fairclough, 1989:26). He maintains that there are certain underlying 'assumptions' behind these selections and that such assumptions are never "innocent"; rather they are "ideologically laden". Hence, by studying the forms of the language it is possible to explore the social processes as well as the ideology embedded in them. This, in turn, could lead to the exploration of the power relations, existing in the social institution or in the community, which determine the "orders of discourse and the underlying ideology". Of course, this does not imply the existence of a 'top-down' relationship or a hierarchical relationship between the society and the discourse. There is, in fact, a mutual relationship between the two. That is, the discourse, in turn, has also a determining effect on the maintenance or the alteration of the power relation. It is crucial to keep in mind that the power relation is mostly practiced implicitly through language and this makes it crucial for the learners to be aware of the impact a language can have on the maintenance or change of such power relations in a community.

To sum up, proponents of CDA tend to discover the ideology or power relation hidden and/ or disseminated through the text. If so, then it seems worthwhile to deal with these issues in more detail.

One of the main objectives of CDA, according to Van Dijk (1998), is to reveal the sources of dominance and inequality observed in the society by analyzing texts (written or spoken). CDA is to reveal the discursive strategies utilized to construct or maintain such an inequality or bias in different contexts. This is due to the fact that texts are not used just to inform us of some reality. They, additionally, based on the ideological standpoints of the person, organization, etc., construct the reality.

Van Dijk, does not exempt any texts from this function. Even a medical text which is expected to impartially portray various illnesses different patients may suffer is no exception and may exhibit certain ideological outlook, leading to sort of discriminations. Then, despite the fact that a medical textbook is not expected to limit itself to the presentation and cure of just certain patients, in reality, it, like all other types of texts, while accomplishing its main tenets, can potentially involve, construct and sustain power differences (Fairclough, 1989; Briggs, 1997; van Dijk, 1998). Hence, medical books, like other books, may not be written to just represent the personal attitude, belief, or even knowledge of the writer. They mirror the perception of the society, as well ( van Dijk, 2001). 
In addition to constructing power relationship, language is actively involved in identity formation; Blummart (2002), in this regard, maintains that the language used in a text contains the elements of identity formation and contributes to the formation of self. Lemke (1985), similarly, states that language plays a crucial role in the making of people; that is, it is constitutive as well as being representative. If so, then the language employed in the book under study has the potential to construct the identity of the patient while representing the attitude of doctors and/or the society toward him/her as well. Like other acts of communication, the doctor and the patient, through interaction, try to establish their own position and convey their own opinion. They categorize and classify each other by resorting to a unique form of communication which reflects their special mindset toward their interlocutor(s). In this regard, the current study tends to discover the ideology or power relation hidden and/or disseminated through the medical texts. This could help to find out how patients are represented in such texts. The study specifically examines the way patients have been illustrated in such texts. It seeks to find out if they have been referred to in a general manner, irrespective of their social status, race, etc., or whether the patients' gender as well as social position is taken into account when they are addressed in the text. Such issues are of special importance because they indicate whether the texts represent the patients of different age, gender and social class equally; if not, and if they book is biased towards certain types of patients, then the medical doctors and students using such texts and/or applying such texts in medical contexts might be misguided.

The present study adopts a sociolinguistics perspective to examine the social status of the patient in the text. This approach takes language as the representation of the stance taken by the speaker (writer) towards himself/herself or/and the addressee. However, as Ochs (1992) maintains this is not a straightforward issue; to realize the function of the text, one has to be equipped with the knowledge denoting the relation between language and gender, among other social relations. Then, (s)he can associate a certain linguistic form to the stance and social action, in addition to the norm, preferences and expectation displaying the identities of the speaker, referents and addressees (p.342). This Approach attempts to see how a linguistic form can perform a certain function within a social context. That is, it is to discover how gender, social status and age can be constructed linguistically. In this regard, Ochs (1992: 341) argues that 'linguistic features may index social meanings (stances, social acts, social activities), which, in turn, help to constitute gender meanings'

The present study, adopting a sociolinguistic approach, examines the way language as a social practice is used in a Persian medical text, written eight centuries ago. The approach taken helps to know how the text represents the medical society in practice at that time. It specifically focuses on the way medical students and physicians are addressed in such texts; it provides a framework for explaining the role of such texts in shaping certain norms and values in their target society.

\subsection{Medical Practice}

In ancient times, medicine and magical practice were intertwined and the magician, or the healer, used to occupy a high social position ( Golesorkhi:2008,467). He, in fact, had one of the most powerful statuses in the society. Later, in an attempt to separate itself from superstition, medicine took a hierarchical stance with the physician, as a knowledgeable person, in the upper position and the patient, as a layman, in the lower rank. Hence, the medical science, though, apparently became scientific in its approach, in fact, followed the same tradition prevalent in older times.

Numerous studies (Farshad,1986; Homaee,1984; Abdollahi,2002) dedicated themselves to finding the origin of medicine as well as realizing where, for the first time, patients practically received medicine and got treated. According to ancient texts (Will Durant,1935) in tribes, witch doctors were in charge of treating patients. In Egypt, for instance, there is ample evidence showing that treating patients was carried out through magical performance (ibid). During the Sumerian era, also, it was known that medicine was a very respectable job and doctors knew how to treat every ailment, but, during this era medicine and religion, rather than magic, were intertwined (ibid).

In western world, the presence of ailment was attributed to the fury of the gods and people used to seek their remedy and here the mediator, again, was a clergyman (Farshad, 1986). Later, physicians such as Hippocrates developed the practical and theoretical medicine. Yet, during the medieval period, the prominent idea was to give priority to the spirit rather than the body and hence hospitals were mostly religious organizations. In the ninth century, for instance, private organizations, named Hospiti were founded in places where travelers used to rest (Farshad, 1986). One good example is Alexander Medical School which swung between the empiricism and traditional healing (Haghighat, 1993). In sum, there were two approaches toward the origin of medicine. While one attributed it to the divine inspiration, the other related it to the imitation of the nature. The latter posited that human beings learned how to treat through observation. The other examples were three medical and medical education centers in Rey, Hamedan, and Perce police which were founded during the Achamenian period ( about 2500 years ago). The hospitals made beside these centers were more sanctuaries in which patient as well as sick soldiers used to be treated.

Avesta, the holy book of Zoroastrian, which, in addition to its religious status, is very rich in Indo-Iranian myth, divided medicine into three branches: "knife therapy", "herbal therapy", and " Manthara therapy", the last was considered as the most important one. Mantra, literally, means "god remember" (Zikr) (vandidad,section 22:2, Ghavidel, 2008). It is interesting to note that, though, in Ancient Iran, medicine took an apparently scientific approach, again the most important branch of medicine was comparatively far from science. That is to say, doctors tend to resort to Zikr to cure the patient. Here, again, there was a one way relationship between the doctor and the patient; from the former, the knowledgeable person to the latter, the layman. This approach continued to exist till the appearance of Islam in Iran, as witnessed by one of the oldest books, entitled, Oyun-al-anba? fi tabaghate-at-atebba ( Literary, Medical Affairs in physician's classification) (Ebn Abi Osaybea, n.d.), in which different medical schools as well as the physicians were 
introduced. The book favoured the idea that medicine was descended to man through inspiration. This is supported by the book Kashf-al-zonun (literary, uncovering hesitation, by Haj Khalife (n.d.)), in which an angel gave medicine, received by god, to certain selected one. So, patients were treated by medicine men who were inspired by some divine ideas. Again, a wide gap was depicted in the book between health care providers and patients. This gap along with some other similar discriminations found in medical books induced the researchers to study medical texts in more detail.

\subsection{Research Questions}

The main question addressed in this study is as follows:

1. What is the implied identity of the patient expressed in the book?

This question can be divided into three sub questions as follows:
a. What is the gender of the patient?
b. What is the approximate age of the patient?
c. What is the social class of the patient?

The writer explicitly and implicitly attributes certain features, such as the social class, gender, and age to the patient. The study, thus, tends to find discursive strategies employed in (re)constructing patients' identity. Reconstructing or constructing the identity of someone or a communit y can be seen in different texts, including medical texts.

With regards to the evidence found in medical texts, the study will show if the patient is treated as an individual and/or an object. Furthermore, the other points of interest in this study are the gender, age and social status of the patient.

\section{Method}

The present study adopts a sociolinguistics perspective to examine the social status of the patient in the text. This approach takes language as the representation of the stance taken by the speaker (writer) towards himself/herself or/and the addressee. However, as Ochs (1992) maintains this is not a straightforward issue; to realize the function of the text, one has to be equipped with the knowledge denoting the relation between language and gender, among other social relations. Then, (s)he can associate a certain linguistic form to the stance and social action, in addition to the norm, preferences and expectation displaying the identities of the speaker, referents and addressees (p.342). This Approach attempts to see how a linguistic form can perform a certain function within a social context. That is, it is to discover how gender, social status and age can be constructed linguistically. In this regard, Ochs (1992: 341) argues that 'linguistic features may index social meanings (stances, social acts, social activities), which, in turn, help to constitute gender meanings' his regard, the present study, adopting a sociolinguistic approach, examines the way language as a social practice is used in a Persian medical text, written eight centuries ago. To this end, the study analyzes the text critically. The approach helps to know how the text affected the medical society in which it was used. It specifically focuses on the way medical students and physicians are addressed in such texts, helping to shape certain norms and values in their target society. The framework also makes use of the Systemic Functional Linguistics, as the baseline of the CDA approach. It uses various analytical tools to analyze a variety of texts ranging from ordinary everyday conversations to political talks, or even military, medical and economic events. The diversity of analytical tools available has made the approach considerably versatile and flexible so that it can be adopted to effectively analyze various texts, from written to spoken ones, using the right analytical tool.

\subsection{The text}

One of the most influential books in this field is "Khoffi Alayee" which is to be analyzed based on the language used. As a commonly used medical text of its own time, the book is expected to reflect the writers', and probably the community's, attitude toward the patient. The main reason for selecting this book is that, in addition to being a scientific text, it is has been of general use as well; it apparently served as a kind of pocket book which could be used at the time of emergency or trips. The reason for calling the book "Khoffi Alayee", which means "Alayee Book", is that it was dedicated to Alā ud-Dīn Atsiz, - Alayee, in short - the young prince of Khwarazmshahian (died 1156). The book was published in two volumes in order that the reader could put each volume in one of his boots while he was away on trip. The book may then be a pioneer for today's pocket books as it has apparently been the first time a book of this size was designed. The size of the book and its application might reflect the role played by the physicians at that time. It brings to the mind the image of a soldier, riding the warhorse toward the battle field, or being prepared to offer help upon requests. The book is divided into two volumes. The first volume comprises two articles, the first containing sixteen and the second seven chapters while the second volume consists of seven articles containing 23 chapters in sum. This volume, as explained by medical experts, in fact, offers comprehensive information on etiology of diseases, treatment as well as personal hygiene. The present study is an attempt to analyze the second volume of the book from the sociolinguistics perspective. More specifically it tends to discern the ways in which patients are depicted in terms of their age, gender and social class. These features are manifested in the linguistic choices the writer makes.

\section{Results and Discussion}

Before introducing the results, it seems pertinent to give an overview of medical practices in Iran in ancient times. Apart from the mythical stories on treating patients, during the Achaemenid period (c. 550-330 B.C.), there were three medical centers (Najmabadi, 1962: pp.18-9). Each center had a hospital at its vicinity which mainly received patients injured in wars. These hospitals were supervised by army officers and hence the hierarchical relationship found in the 
army was transmitted to the hospital in which the doctors were authoritative figures, while the patients, treated as an object, had no authority.

During the Khwarazmshahian era (13th Century), there were many wars with most people being involved in. The high frequency of wars prompted the young prince, Ala ud-Din Atsiz, to order the writing of the book Khoffi Alayee in pocket size so that the carrier could take them in his booths while on trip. Such trips apparently were kinds of war missions, as witnessed in the word "booth" found in the title of the book. The war itself in old times was referred to as the best school for practicing and learning surgeries by Hypocrites, as cited in Najmabadi (1962), implying that patients were considered as objects to work on. Another evidence on how the patient was looked upon is that a doctor, in order to get the medical license, first had to treat at least three patients who were not faithful to any religion and accordingly were labeled as pagans; the inexperienced doctor, in fact, first had to perform some practice on such patients, with no concern about the potential risks that could threaten their lives (Najmabadi, 1962). Alexander School was one of the oldest known medical schools which, due to the presence of a number of distinguished physicians, contributed to the prevalence of a scientific atmosphere. In this school, for the first time dissection of the bodies was allowed. Here, since the dissecting of the corpse was very important for the physicians, they were allowed to dissect the prisoners, sentenced to death, alive. Dissecting the prisoner, while still alive, is a strong proof of physicians' attitude toward their patients.

\subsection{Patient as an Object}

The book, Khoffi ,also, at times, seems to treat the patient as an object. This can be shown through the absence of faceto-face communication between the doctor and the patient; the doctor does not directly communicate with the patient at all ; This attitude might have encouraged the doctor to adopt a formal approach toward the patient, which is indicated by the structure of the statements used. The doctor, for example, uses passive structures to refer to the patient. In active voices also the doctor uses the plural 'they'. In addition, the doctor seldom talks to the patient directly; instead, almost always, he addresses the patient's relatives. The following is an example about a patient suffering from a mild fever.

EX: To relieve fever, the home should be cooled down but the patient should be worn a kind of clothes so that the cold air could get into his lungs, not his body.

Following this general instruction, the doctor talks to the servants and/or care givers of the patient and gives them the required prescription. The 'home' and the 'patient' both are passivized, but comparing 'the patient' with 'the cold air' in the above sentence, we see that while the patient is passivized, getting dressed, the air is active and can get into his lungs; This shows how the patient is objectified. Furthermore, the patient has somebody to help him to get dressed and is rich enough to choose a kind of clothing suitable for that weather.

EX: They should wet the cotton material with the white Santalum album ( a kind of scented herb) soaked into rose water and ginger; They should put the wet material on the forefront and temples. They should also wash the feet in the water in which violet flowers and Chamaemelum are boiled and treat constipation with suppositories made from violet flower, sugar and scamony. (p.13)

For the food and medicine someone else (a member of or one of relatives) should take care. Here also the patient is not addressed directly. The servants or relatives, referring to as 'They' are, in fact, active- the doers- while the patient is totally absent.

\subsection{The Gender of the Patient}

In this book, there is ample evidence indicating that the patient is a male, not a female. That is to say, the patient is meant to be a male unless it is stated otherwise. Out of 256 pages of the book, fewer than four pages (less than 1.5\%) are devoted to females and their illnesses, such as, pregnancy, breast feeding, infertility, and the like.

This is realized through the type of clothes, masculine actions and personal care the writer refers to. Consider the following examples:

\subsubsection{Clothes}

Example 1: 'The person while traveling in warm areas, should cover his head'. (p.85)

It should be noticed that women's covering of the head, as a social obligation, was taken for granted in the 12th century in Iran and, therefore, the writer did not need to mention it in the text; therefore the term 'person' referred to in such examples must refer to a male subject.

Example 2: 'When the person is crossing cold places should cover his toes with goat fur ( called PATABE, in Persian) and use a kind of shoes( called MU:ZE)'. ( page 86)

This is a very clear reference to male individuals as the women always had to cover their toes. So, in addition to the type of shoes, which seems to be male specific, the covering of the toes is clear evidence indicating a male subject. In addition, the word 'PATABE' refers to as a kind of shoes worn by males only.

\subsubsection{Masculine actions}

Among the actions attributed almost exclusively to men is that of riding the horse or the like, especially when the person is alone and on a trip. Then, there will be no doubt that the person is a male. The verb frequently used for traveling is "Barneshestan" ( literally means 'sit on') but actually it means just sit on the horse back or other animals; this also refers to a masculine action. The doctor is advising the patient not to go on trip permanently. A woman is not usually expected to take on a permanent trip. 
Example1. : The person who is on trip should ride the horse, camel, etc. intermittently, not permanently. (p.85)

Example 2: The patient with fever will become sexually impotent in case he consumes hot medicine. (p.211)

The above prescription is the first sentence written in unit one, focusing on the issue of impotency. Such issues exclusively take males into account.

Example3. : If a house is to be constructed, the patient should construct it in the following way :( p.18)

The addressee of the above sentence is more likely to be a man since constructing a house or even supervising the construction is usually within the realm of a man than a woman.

3.2.3 Personal care

One may expect issues such as personal care to be of concern to both females and males. In this book, however, the evidence shows a strong bias toward addressing males.

While advising the patient, the doctor is most likely referring to a male patient. There are ample examples bearing witness to this.

Example 1: It is recommended that the patient stay at home, not outdoor when the weather is not favorable. ( Gorjani, 1369, 1999 p.10)

This sentence more likely refers to a male subject as women in this culture were expected to stay in, even without the physician's request.

Example 3: The clothes worn should be soft and made of the fur of animals such as squirrel, fox, Angoria goat, etc.,

The above sentence states that the patient needs to wear soft and warm clothes. Again, it is understood that the patient is more likely to be male; in this culture, a man, rather than a woman, normally works out and hence has to wear clothes suitable for such weather.

Furthermore, from the remedy and instruction given by the doctor for diseases such as those related to bladder and sexual organs, one can realize that the patient cannot be a female. (pp.208-212). More specifically, in chapter four, about inflammation and infection, the writer names the male sexual organ and discusses important sexual behavior and gives recommendations which can only refer to males.

\subsection{Age of the Patient}

There are plenty of examples denoting that the patient is young; the old and the young children are treated as marked ones and hence the adjectives (old/young) or other similar modifiers would accompany such children.

Example 1: Chapter four, section 7 discusses different types of wine the patient can drink, all implying that the patient is young because when the doctor meant an old one, he specifically states that the old person can drink this type of wine. This is seen only once in the book. Here (p.35), the patients are recommended to drink a special kind of wine, i.e., a kind of wine different from what others ( younger people ) drink.

In addition, young children are refrained from drinking wine. This implies that different types of wine discussed can be drunk by the young. (pp.34-37). So, the person, under discussion, is not old.

Example 2: However, those who do a light sport and those who are old should eat less and refrain from eating fat (p. 24).

This is one of the rare cases that the person addressed is old; this implies that in all other cases the person is not old.

On page 35, the writer divides people into 5 groups: healthy people, old people, children, slender people, and those with weak speech ability. It is interesting that the old people and children are not classified under the category named 'healthy people; they are, by nature, far from being healthy, or at least strong. Hence, the young appeared to be unmarked and hence those whom the book addresses.

\subsection{Social Status}

Concerning the social status of the patient, the writer communicates his image of the patient to the reader through the instruction given:

\subsubsection{Food}

The patient is rich because during the time when there are few varieties of food he is advised not to eat too much. Also different types of food are recommended as supplements for the treatment. So the patient must have sufficient income to order various types of diet; otherwise he cannot afford purchasing the diet.

Example 1: It is recommended not to eat too much; otherwise he should excrete the excess by either taking certain medicine or vomiting it (pp.22-23).

Example 2: It is recommended to walk a little after eating because the food may remain at the cardia, the opening of the stomach, and walking makes it go down (P.23).

This also implies that the patient is rich because he can afford eating too much.

Example 3: The person is advised to eat the food in certain order; that is the main food such as meat should follow other types of foods such as soup, fish, milk, etc. (P.23). 
It is obvious that ordinary people did not have access to a variety of food.

Example 4: He is recommended to refrain from eating certain foods (p.23) during his leisure time or while doing sports.

Again it is understood that the person is rich enough to have leisure time, doing sport

Example 5: When the person overeats, he should take a long rest and the following day, he should do a light sport (P.23).

This implies that he is rich as he can eat a lot and take long rest.

\subsubsection{House}

The following examples also show that the patient must be rich enough to afford building a house with numerous rooms and a high ceiling. Furthermore, at the time when people used to go to public bathroom, he could have a private one and was advised to use herbals to soften his body.

Example 1: If a house is to be constructed, the patient should construct it in the following way: all rooms should face the east and they should have wide doors. Furthermore, they should have high ceilings (p.18).

Example 2: After doing some exercises, the person should bathe in warm water with some herbals and natural oil so that his body softens.

\subsubsection{Clothes}

Other pieces of evidence denoting that the patient is wealthy are those related to clothes, as exemplified below:

Example 1: The clothes which are worn under the coat ,.. and the underwear, which are washed by the workers, should be cotton, silk, etc., depending on the weather( p.20).

This implies that the patient is rich enough to have a servant.

Example 2: For those who cannot sleep soundly, they should cover themselves, especially their stomach with fur, or have someone to sing a song for them or to sleep in a place where they can hear the sound of water or the mill.

\subsubsection{Means of transportation}

Means of transportation may also give witness to the claim that the patient is rich and belongs to a high social class.

Example 1: The person, on trip, rides the horse (p.85), camel, etc., intermittently, not permanently.

This person is rich enough to own a horse or the like.

\subsubsection{Medicine}

The medicine suggested is usually rare and expensive.

Example 1:HEJAMAT Fasd: Such people should take medicine most of which are very rare and hence expensive, such as quince wine, Greater plantain, Armenian bole, Arabic Gum, rosewater, philonium romanum, etc. (pp. 50-1)

There are plenty of examples about the medicine.

The old and children should not FASD ( to cut veins); that is the person addressed are normally young or middle-aged unless directly stated otherwise. Throughout the book, just one page of a section (chapter 15) is dedicated to the poor or children. This implies that the rest of the book, except for two or tree times, the writer is addressing a person who is not old.

\subsubsection{Servant}

Other examples denoting that the patient is rich are shown below. He is rich enough to have one or more servants as witnessed in the following examples:

Example 1: If the person has difficulty sleeping, he should have some people read books or tell stories until he falls asleep. Then they should leave the room very quietly.

Example 2: In the morning, before and after doing exercises, the person should have his servant(s) massage his body.

Example 3: The clothes worn should be soft and made of the fur of animals such as squirrel, fox, Angoria goat, etc.

All this implies that the patient is affluent.

\section{Conclusion}

The study analyzed a $12^{\text {th }}$ - century medical text to identify the way patients were looked upon in the medical context. The analysis could help to explore the identity of the patient in medical encounters of that era. The analysis specifically addressed (a) the gender, (b) approximate age and (c) social class of the patient.

As the examples cited above indicate, the book represents the writer's subjective views toward the patient, downgrading the status of the patient from an independent individual with the rights to be involved in direct verbal (communicative) exchanges to an inferior citizen who does not need to be involved in medical exchanges. He is viewed primarily as an object without the social status considered for revered citizen. On the other hand, in rare occasions, when he is treated as a person, he represents an individual belonging to the middle or higher classes of the society. 
Concerning the diction of the book, the following example gives witness to the attitude of the writer toward the gender of the patient. The word "public", for instance, is commonly used to both males and females, but a close look at the text shows that the word is used to refer to a male subject only.

The book gives certain instruction in case of vomiting (P.P.73-4); vomiting is used as an umbrella term referring to whatever comes out of the body, whether, from the mouth, the rectum or the sexual organs. The book apparently addresses the 'public' but a closer look shows that the addressee should be a male, not a female; The book, continues talking about the benefits of excreting what comes out of the sexual organ, the male sexual organ.

As the examples indicate, the text mostly under-represents, the elderly, children by primarily the middle age male patients.

The way the language, as a social practice, is used in medical texts is of special significance, since language is the medium through which our outlook toward the world is shaped. Medical texts are supposed to be written impartially (objectively) without taking side, overtly or covertly, in favor of a particular social group. Nonetheless, when it comes to true world of publications (e.g. texts or books), the reverse is happening and medicine is not an exception. Publications, particularly in text form, from old days till now tend to construct and sustain power difference (Briggs, 1997), while trying to accomplish their main objectives - communication of field-specific knowledge and information. If the way different social groups are represented in such texts is left unattended, the consumers of the texts might be misguided by being indirectly influenced by the authoritative relations hidden behind prefabricated messages of the text.

Hence, in sustaining power differences or inculcating the intended meaning, even the medical texts are not (left) immune; in our case, the texts did not represent the patients of different age, gender or social classes. The medical students and the doctors using such books might be exposed to (might receive) an incomplete account of the relevant community, which can unduly affect their practice. Therefore, by scrutinizing medical texts, as common forms of discourse, with a vast array of records, dating back to many centuries ago, we can obtain invaluable information about power relations and social interactions which could help pave the way for better relations in our future communities.

\section{References}

Abdollahi, M. (2002). Farhangnameh-ye Janevaranin dar adab-e parsi (The Dictionary of Animals in Persian Literature). Tehran: Pajoohande.

Blommaert, J. (2002). Orthopraxy, writing and identity: shaping lives through borrowed genres in Congo. Working Papers on Language, Power \& Identity $N^{\circ} 12$.

Briggs, Charles. (1997). Notes on a 'confession': On the construction of gender, sexuality and violence in an infanticide case, Pragmatics, 7, 4, 519-546.

Bourdieu, P. (1977). Outline of a theory of practice. Cambridge University Press: London.

Chapelle, Carol A. (1998). Some notes on systemic-functional linguistics. Retrieved from

www.public.iastate.edu/ carolc/ LING511/ sfl.html

Durant, W. (1935). The history of civilization, vol.1: Our Oriental Heritage. New York: Simon and Schuster.

Ebn Abi Osaybea (n.d.). Oyun-al-anba? fi tabaghate-at-atebba( Medical Affairs in physician's classification).

Fairclough, N. (1989). Language and power. London: Longman.

Fairclough, N. (1995). Critical discourse analysis. London: Longman.

Farshad, M. (1986). The history of science in Iran. Tehran: Amirkabi.

Fowler, R. (1996).On critical linguistics. In Coulthard, C. \& Coulthard, M. (eds.) Texts and Practices. London, UK:

Routledge.

Ghavidel, H. (2008). The history of medicine in ancient Persia. Retrieved from

http://irantoday.co.kr/lse/2008/01/30/469/

Golesorkhi, Iraj(1377 H. -2008). The history of magician ( In Persian : Tarikh -e- Jadoogari) . Tehran: Elm Publication.

Haghighat, A. (1993). Tarikh-e oloom va falsafe-ye Irani (literary, The History of Science and Philosophy in Iran). Tehran: Koomesh.

Haj Khalife (n.d.). Kashf-al-zonun (literary, uncovering hesitation)

Halliday, M.A.K. (1989). An introduction to functional grammar. London: Edward Arnold.

Halliday, M.A.K. (1969). Relevant models of language. Educational Review 23, 165- 88.

Hammersley, Martyn (1997). On the foundation of critical discourse analysis. Language \& Communication, 17, 237248 .

Homaee, J. (1984). The history of islamic sciences. Tehran: Homa. 
Kress, G. (1996). Representational resources and the production of subjectivity. In Carmen Rosa Caldas-

Coulthard \& M. Coulthard (eds), Texts and practices (pp. 15-31). London: Routledge.

Lemke, J.L. (1985). Ideology, intertextuality, and the notion of register. In J.D. Benson and W.S. Greaves (Eds.), Systemic Perspectives on Discourse. (pp. 275-294). Norwood, NJ: Ablex.

Najmabadi, M. (1962). Tarikh-e teb-e Iran ( The history of Medicine in Iran). Tehran: Honarbakhsh.

Ochs, Elinor (1992). Indexing gender. In Duranti, A. \& Goodwin, C. (Eds.), Rethinking context: Language as an Interactive Phenomenon (335-358). Cambridge: Cambridge University Press.

Pennycook, Alastair (2001). Critical applied linguistics: a critical introduction. NJ: Lawrence Erlbaum Associates Inc. Derived from: www.education.uts.edu.au/astaff/staff/pennycook_cal.pdf

Schiffrin, D., Deborah Tannen, \& Hamilton, H. E. (eds.). (2001). Handbook of Discourse Analysis. Oxford: Blackwell. van Dijk, Teun A. (2001). Discourse, ideology and context. (Second draft, July 3, 2001). Derived from:

www.hum.uva.nl/ teun/cda.htm

van Dijk, Teun A. (2000). Ideology and discourse: A multidisciplinary introduction. Barcelona: Pompeu Fabra University.

van Dijk, T.A. (1998). Critical discourse analysis. Derived from: www.hum.uva.nl/teun/cda.htm

van Dijk, Teun A. (1997a). Political discourse and political cognition. Paper Congress Political Discourse, Aston University July 1997. Retrieved from van Dijk’s homepage Web-site: www.let.uva.nl/ teun

van Dijk, Teun A. (ed.) (1997b). Discourse Studies. 2 vols. London: Sage 